Research Article

\title{
Impacts of Emission Reduction Technological Changes on China's City-Level PM2.5 Concentration Based on Sustainable Development
}

\author{
Jiandong Chen $(\mathbb{D}$, Yu Wei $(\mathbb{D}$, Ming Gao $(\mathbb{D}$, and Shuo Huang $(\mathbb{D}$ \\ School of Public Administration, Southwestern University of Finance and Economics, Chengdu 611130, China \\ Correspondence should be addressed to Ming Gao; minggao1994@163.com
}

Received 5 October 2021; Accepted 11 November 2021; Published 24 November 2021

Academic Editor: Xuan Song

Copyright ( $) 2021$ Jiandong Chen et al. This is an open access article distributed under the Creative Commons Attribution License, which permits unrestricted use, distribution, and reproduction in any medium, provided the original work is properly cited.

\begin{abstract}
As an important field for human activities, cities play a critical role in PM2.5 reductions. Among the determinants for PM2.5 concentration, technological progress is considered to exhibit significant inhibitory effects. Although most extant research has focused on energy technologies or total factor productivity, due to limitations in data and methods, few scholars have focused on emission reduction technological changes at a city-level scale. Therefore, based on the combination of $k$-means clustering and the log-mean Divisia index method, this study estimates and explores the impact of PM2.5 emission reduction technology (PME) on the temporal changes and spatial differences of 262 Chinese cities' PM2.5 concentration during 2003-2017. The findings show the following: (1) although the results based on econometric methods indicate that emission reduction technological changes decreased China's city-level PM2.5 concentration, there were turning points in the yearly impacts, indicating that the improvements to emission reduction efficiency were not stable; (2) compared with PME, energy intensity played a more stable role in PM2.5 emissions reductions, implying that the improvement of energy efficiency was still very important in controlling PM2.5 concentrations; (3) based on the classified groups after clustering, most cities' PME contributed to negative differences, but the PME of a small number of cities was very weak to largely lower the average level of their group; and (4) distributions of the spatial decomposition of the three classified groups were stable in the period of 2003-2017, implying that the catch-up and transcendence effects of PME within the group were limited. Thus, policymakers should focus on the impact of different policies on PME differences between cities.
\end{abstract}

\section{Introduction}

In recent years, PM2.5 pollution has seriously concerned countries around the world due to the threats it represents to human survival and to the sustainable development of society [1-3]. In light of previous studies, PM2.5 emissions can not only lead to high haze reduction costs but also indirectly cause health costs through medical expenses and work-time loss. In particular, the emissions control cost in Shanghai would be about $1.01 \%-2.26 \%$ of the corresponding gross domestic product (DDP) values in 2030 [4]. And the direct external cost of residential health issues caused by PM2.5 pollution in Beijing and Changsha was as high as $0.3 \%-2.69 \%$ of the GDP during 2012-2017 [5, 6].
As one of the world's largest developing countries, China is undergoing a process of accelerating urbanization and industrialization, facing increasingly severe PM2.5 pollution $[7,8]$. Thus, the government has focused on formulating a series of policy regulations, such as the Air Pollution Prevention and Control Law, switching from coal consumption to natural gas consumption, and setting emission reduction targets for PM2.5 concentration in the 12th Five-Year Plan (2011-2015) [9, 10]. At the same time, many actions have also been taken to monitor PM2.5. For example, China has established thousands of PM2.5 monitoring observatories, which have been reporting hourly and daily air quality since 2012. Additionally, China's grassroots government has intensified supervision of straw burning in rural areas to curb haze pollution. 
Concurrently, an increasing number of scholars have begun to pay attention to the field of PM2.5 pollution and have provided some corresponding policy implications with respect to curbing it. Given that PM2.5 concentration has mainly been driven by human activities, such as vehicle emissions, power generation, and industrial production, many studies have paid specific attention to the impacts of socioeconomic drivers on PM2.5 pollution [11-14]. For example, Ma et al. [15] analyzed the relationships among GDP per capita, the price of refined oil, vehicle population, energy intensity, and PM2.5 concentration in 152 Chinese cities based on spatial linkage and found that the impacts of economic, social, and energy efficiency on different cities varied significantly. Similarly, Zhang et al. [16] used the log-mean Divisia index (LMDI) method to break down changes in the PM2.5 concentration in these 152 cities. Their results showed that the decline of PM2.5 concentration was mainly driven by energy intensity and emission intensity, while GDP per capita and population were responsible for the increasing PM2.5 concentration. Among the driving factors of PM2.5 concentration, many socioeconomic factors have been found to contribute to the increase in PM2.5 emissions and concentration. These factors, such as increasing urbanization, economic growth, and population growth, are difficult to reduce in order to decrease PM2.5 pollution. Therefore, several studies have focused on factors that directly contribute to reducing PM2.5 pollution.

Among many economic factors, technological progress has been considered to play an important inhibitory role $[17,18]$. In particular, Chen et al. [18] studied the effects of foreign direction investment, export learning effects, research and development, and import technology on the reduction of PM2.5 concentrations in 48 Chinese cities during 2000-2015. Likewise, Li et al. [19] used spatial econometric models to study the potential relationship between environmental total factor productivity and 283 Chinese cities during 2000-2013. Similarly, Xu et al. [20] analyzed the impacts of total factor productivity on 281 prefecture-level cities in China from 2007 to 2017 based on a spatial dynamic panel model, concluding that technological progress has significant positive effects on alleviating PM2.5 concentration. In total, these studies have only considered energy technologies or total factor productivity, ignoring the effects of PM2.5 emission reduction technology (PME). There is no doubt that improvements to energy efficiency can reduce energy input and decrease PM2.5 emissions; however, there is a need to pay more attention to PME changes, since these determine the PM2.5 pollution produced under the same unit of energy consumption and economic output and directly influence the level of cities' sustainable development.

In the light of existing literature, although scholars have studied the impacts of drivers on PM2.5 pollution in China's prefecture-level cities from a socioeconomic perspective, the current literature on PM2.5 concentrations has several shortcomings. (1) Some scholars have analyzed the impacts of technological progress on PM2.5 pollution, but few studies have examined the impacts of PME changes on China's city-level PM2.5 pollution; (2) many studies have concluded that there is significant spatial and temporal heterogeneity in the determinants of PM2.5 pollution based on spatial econometrics, but have not outlined detailed temporal changes; and (3) although some scholars have used the LMDI method to analyze determinants of temporal PM2.5 pollution changes, they have not considered spatial differences, especially within classified groups.

Hence, this study explores the impacts of PME changes on PM2.5 concentrations of 262 Chinese cities during 2003-2017. First, we applied three spatial econometric models (SDM, SAR, and SEM) to identify the spatial autocorrelation and potential relationship between PME changes and PM2.5 concentrations. Next, we decomposed the temporal and spatial changes in the PM2.5 concentrations of the 262 cities based on the combination of LMDI and $k$-means clustering methods. Our study makes the following contributions and findings: (1) we estimate the PM2.5 PME of 262 cities and analyze its impacts on China's city-level PM2.5 concentration; (2) the results show that there have been turning points in the yearly impacts, indicating that improvements to the emission reduction efficiency have been limited and unstable; and (3) based on the combination of $k$-means clustering and spatial LMDI methods, we find that the gaps among the spatial decomposition in our classified three groups were stable in the period 2003-2017, implying that the ranking of the emission reduction technology development level of each prefecturelevel city in each group was relatively stable.

\section{Materials and Methods}

2.1. Spatial Impacts of PME on PM2.5 Concentrations. In light of the modified production-theoretical decomposition analysis method proposed by Wang et al. [21], we first estimated the PME during 2001-2017. We selected three input factors, one desirable output, and one undesirable output: fixed capital stocks, employed population, energy consumption, real GDP, and PM2.5 concentrations. The calculation of PME was based on the Shephard distance functions:

$$
\begin{aligned}
& \mathrm{D}_{p m}^{s}\left(K_{i}^{t}, \mathrm{~L}_{i}^{t}, E_{i}^{t}, P M_{i}^{t}\right)=\min \theta \\
& \text { s.t. } \quad \sum_{n=1}^{N} z_{n} E_{n}^{s} \leq E_{n}^{t}+\tau_{n}, \\
& \sum_{n=1}^{N} z_{n} K_{n}^{s} \leq K_{n}^{t}+\tau_{n}, \\
& \sum_{n=1}^{N} z_{n} L_{n}^{s} \leq L_{n}^{t}+\tau_{n}, \\
& \sum_{n=1}^{N} z_{n} Y_{n}^{s} \geq Y_{n}^{t}, \\
& \sum_{n=1}^{N} z_{n} P M_{n}^{s}=\theta P M_{n}^{t}, \\
& z_{n} \geq 0, \quad n=1, \ldots, N, \\
& \tau_{n} \geq 0, \quad n=1, \ldots, N, \\
& s, t \in\{0, T\}, \\
& s \neq t,
\end{aligned}
$$


where $K$ represents fixed capital stocks, $L$ represents labor force, $E$ represents energy consumption, $P M$ represents PM2.5 concentration, $Y$ represents gross domestic output, and $\theta$ represents PM2.5 reduction efficiency.
Thus, the PME can be estimated using the following equation:

$$
P M E=\left(\frac{D_{p m}^{t}\left(K_{i}^{t}, L_{i}^{t}, E_{i}^{t}, P M_{i}^{t}\right) \times D_{p m}^{t+1}\left(K_{i}^{t}, L_{i}^{t}, E_{i}^{t}, P M_{i}^{t}\right)}{D_{p m}^{t+1}\left(K_{i}^{t+1}, L_{i}^{t+1}, E_{i}^{t+1}, P M_{i}^{t+1}\right) \times D_{p m}^{t}\left(K_{i}^{t+1}, L_{i}^{t+1}, E_{i}^{t+1}, P M_{i}^{t+1}\right)}\right)^{(1 / 2)}
$$

where $P M E$ denotes emission reduction technological changes.

Based on previous studies [22], we further used spatial econometric methods to explore the potential spatial impacts of PME on PM2.5 concentration. The spatial models of Durbin (SDM), autoregression (SAR), and error (SEM) were selected. The normal form of spatial econometric model is given as

$$
P M=\lambda W P M+X \beta+\theta W X+\varepsilon,
$$

where PM represents PM2.5 concentration, $X$ represents explanatory variables, $W$ is the spatial distance weight matrix, and $\varepsilon$ is the error term. We used the reciprocal of the geographical distance of the city center to construct the spatial econometric weight.

\subsection{The Temporal and Spatial LMDI Methods. Although} spatial regression methods have the ability to reveal potential relationship between the expected values of PME and PM2.5 concentrations, they ignore temporal and spatial changes. Thus, we used the index decomposition analysis (IDA) method to analyze the yearly and spatial impacts of PME on PM2.5 concentration. In light of previous studies (e.g., $[11,16])$, the IDA identity of PM2.5 concentrations can be described as follows:

$$
P M_{i}^{t}=\frac{P M_{i}^{t}}{E_{i}^{t}} \times \frac{E_{i}^{t}}{Y_{i}^{t}} \times \frac{Y_{i}^{t}}{P_{i}^{t}} \times P_{i}^{t}
$$

where $P M_{i}^{t}$ denotes the ith city's PM2.5 concentration in period $t, E_{i}^{t}$ represents the $i$ th city's energy consumption in period $t, Y_{i}^{t}$ is the $i$ th city's real gross domestic productivity in period $t$, and $P_{i}^{t}$ denotes the $i$ th city's population in period $t$.

Based on a proposition by Zhou and Ang [23], we can obtain the following equation:

$$
\begin{aligned}
P M_{i}^{t}= & \frac{P M_{i}^{t} /\left(D_{P M}\left(E_{i}^{t}, K_{i}^{t}, L_{i}^{t}, P M_{i}^{t} ; t\right) \times D_{P M}\left(E_{i}^{t}, K_{i}^{t}, L_{i}^{t}, P M_{i}^{t} ; 0\right)\right)^{0.5}}{E_{i}^{t}} . \\
& \times \frac{E_{i}^{t}}{Y_{i}^{t}} \times \frac{Y_{i}^{t}}{P_{i}^{t}} \times P_{i}^{t} \times\left(D_{P M}\left(E_{i}^{t}, K_{i}^{t}, L_{i}^{t}, P M_{i}^{t} ; t\right) \times D_{P M}\left(E_{i}^{t}, K_{i}^{t}, L_{i}^{t}, P M_{i}^{t} ; 0\right)\right)^{0.5} .
\end{aligned}
$$

To simplify equation (5), it can be written as follows:

$$
P M_{i}^{t}=P P M E_{i}^{t} \times E I_{i}^{t} \times P I_{i}^{t} \times P_{i}^{t} \times P M E_{i}^{t},
$$

where $P P M E_{i}^{t}$ denotes the $i$ th city's potential emission intensity of PM2.5 concentration without technological change's impacts in period $t ; E I_{i}^{t}$ represents the ith city's energy intensity in period $t$, which reflects energy efficiency; $P I_{i}^{t}$ represents the $i$ th city's GDP per capita in period $t$; and $\mathrm{PME}_{i}^{t}$ represents the $i$ th city's PM2.5 emissions efficiency in period $t$, whose changes reflect the changes in PME.

Next, considering that there may be strong spatial heterogeneity in the effects of PME, we adopted a spatial clustering decomposition analysis method in this study. As described by Cheng et al. [24], this method entails a combination of spatial index decomposition analysis and clustering methods. In particular, we adopted the LMDI method to study the impacts of the five driving forces on PM2.5 concentrations because it is robust, easily understood, and has clear economic meaning. Appendix A presents the formula of the temporal and spatial LMDI method, which can indicate the temporal and spatial impacts of the five driving forces on PM2.5 concentration.

2.3. The Cluster Method. Regarding traditional spatial LMDI method, it is necessary to select a reference for the spatial index decomposition analysis. Normally, the average of total samples' may be used as a reference. However, it will ignore heterogeneity between and within groups. Thus, the clustering method was adopted in this study to combine with the traditional spatial LMDI method, better capturing differences between and within groups.

With regard to the clustering method, hierarchical and nonhierarchical cluster methods are the two main approaches used. The algorithms of hierarchical cluster analysis are related to the construction of the tree structure of clusters, while that of nonhierarchical cluster analysis aims to classify objects into a 
predetermined number of disjointed clusters. Thus, we use a nonhierarchical cluster to make classifications among the observed cities. In particular, we selected $k$-means clustering because the algorithm has exhibited high efficiency and empirical success $[25,26]$ and has been widely adopted in many fields of study, such as environmental analysis, image classification, and so on $[24,27]$. However, the operations of $k$ means clustering analysis need to assume the number of center points in advance, leading to some uncertainty. To overcome this disadvantage, we first used hierarchical cluster analysis based on the shortest Euclidean distance to identify the dendrogram and classifications [28] so as to provide a more intuitive and reasonable reference for the number of center points selected for $k$-means methods.

Additionally, with regard to the cluster indicators, the cities' PM2.5 concentrations and GDP in 2017 were considered. Given that the PM2.5 emission intensity (i.e., ratio of PM2.5 concentration to GDP), like carbon intensity, has often been used to represent the level of PME [16], PM2.5 concentrations and GDP would perform well in revealing the clustering and classifications of PME. Thus, we selected cities' PM2.5 concentrations and GDP in 2017 for this purpose.

The resulting dendrogram based on hierarchical cluster analysis is presented in Figure 1. From the dendrogram, we can clearly observe the clustering process of each sample. In total, 262 cities can be divided into 28 categories based on the shortest Euclidean distance. From the right to left, the 18th category can be regarded as a single big category, and the 17 th category can also be regarded as a separate category. In addition, the 23rd category and the remaining categories can be combined into one big category. Therefore, we speculated that the cities may be classified into three categories. Thus, we preset the number of center points as three. Next, based on the main idea of the $k$-means clustering algorithm, we continuously optimize the selection of the center points according to the Euclidean distance between each point and the center point, until the center points are stable.

2.4. Data. Using the equations above, city-level data were derived for PM2.5 concentrations, energy consumption, fixed capital stock, population, and real GDP. Given the availability of PM2.5 concentration and fixed capital stock data, this paper focused on 262 cities, and the research period spanned from 2003 to 2017.

The data for PM2.5 concentrations were obtained from the real-time monitoring of the Ministry of Ecology and Environment monitoring site (https://106.37.208.233: 20035). We estimated the data for city-level energy consumption based on city-level $\mathrm{CO}_{2}$ emissions, as proposed by Chen et al. [29], due to the significant relationship between energy use and $\mathrm{CO}_{2}$ emissions. The economic output was taken from the China Statistical Yearbook (2003-2017). To avoid the influence of price, we used the price in 2001 as the constant price and obtained the real GDP, which is consistent with the approach used by Chen et al. [30]. Additionally, we calculated the fixed capital stock based on the perpetual inventory method, which is consistent with Chen et al. [31].

\section{Results and Discussion}

3.1. The Results of Spatial Regressions. Based on the spatial econometric method outlined in Section 2.1, we used fixed effects, spatial Durbin (SDM), autoregression (SAR), and error (SEM) models to analyze the relationship between PM2.5 concentrations and PME. In line with Hao et al. [32], we selected GDP and population as the control variables. Table 1 shows the results. Among them, $P$ denotes population and $Y$ denotes GDP.

Column (1) shows that there was a significant negative relationship between PM2.5 concentrations and PME, indicating that PME helpfully reduced PM2.5 concentrations. Columns (2)-(4) imply that there should be spatial heterogeneity. At the same time, the SDM and SAR models individually report the direct, indirect, and total effects of PME progress, indicating that the impacts of PME on different regions' PM2.5 concentrations may vary by regions. In total, the regressions results indicate that China's PME has generally reduced the cities' PM2.5 concentration.

\subsection{Drivers of the Temporal Changes in PM2.5 Concentrations.} Based on the temporal LMDI method outlined in Section 2.2, we categorized the city-level changes in PM2.5 concentrations into five main driving forces that pertain to the influences of energy use. Given that there are no official data about city-level energy use, some scholars have used electronic power consumption to replace total energy use. However, such replacement may cause significant errors, since fluctuations in electronic power use are inconsistent with total energy combustion. Therefore, we calculated the energy use of the 262 cities during 2003-2017 based on data on city-level $\mathrm{CO}_{2}$ emissions, as proposed by Chen et al. [29].

Considering that the calculation of city-level $\mathrm{CO}_{2}$ emissions followed a top-down approach (i.e., provinces and cities), the corresponding city-level energy use can be estimated according to city-level $\mathrm{CO}_{2}$ emissions and the relationship between provincial $\mathrm{CO}_{2}$ emissions and energy consumption. To capture the provincial differences in the ratio of $\mathrm{CO}_{2}$ emission to energy use, we used the varied coefficient model to conduct a regression between provincial $\mathrm{CO}_{2}$ emissions and energy consumption during 1997-2017. At the same time, to avoid the negative values of city-level energy use, we used a no-constant model. Table 2 in Appendix A presents the results.

Evidently, the coefficient of determination was 0.986 , implying that the estimated city-level energy consumption was highly accurate. Based on the city-level energy use, we can obtain the impacts of driving forces on the PM2.5 concentrations of the 262 cities.

To capture more temporal fluctuations of PME impacts, we divided the period of 2003-2016 into four parts: 2003-2006, 2006-2009, 2009-2012, and 2012-2017. These results are presented in Figure 2. They show that not all cities' PME continuously decreased the PM2.5 concentrations during 2003-2017, and detailed information thereon cannot be found based on regressions. At the same time, 


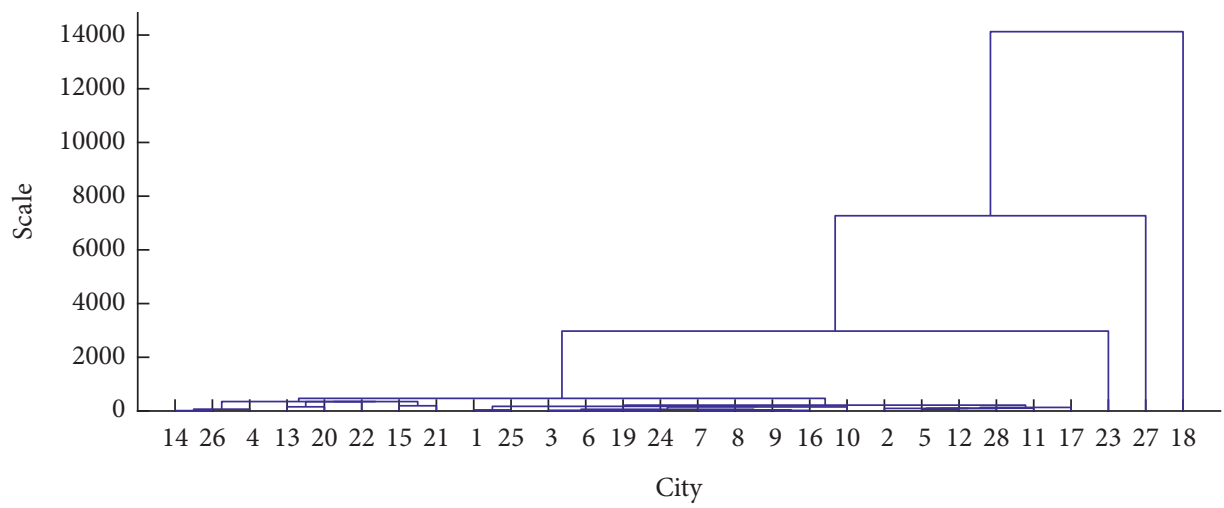

FiguRE 1: Hierarchical cluster results.

TABle 1: Spatial econometric results of the four models.

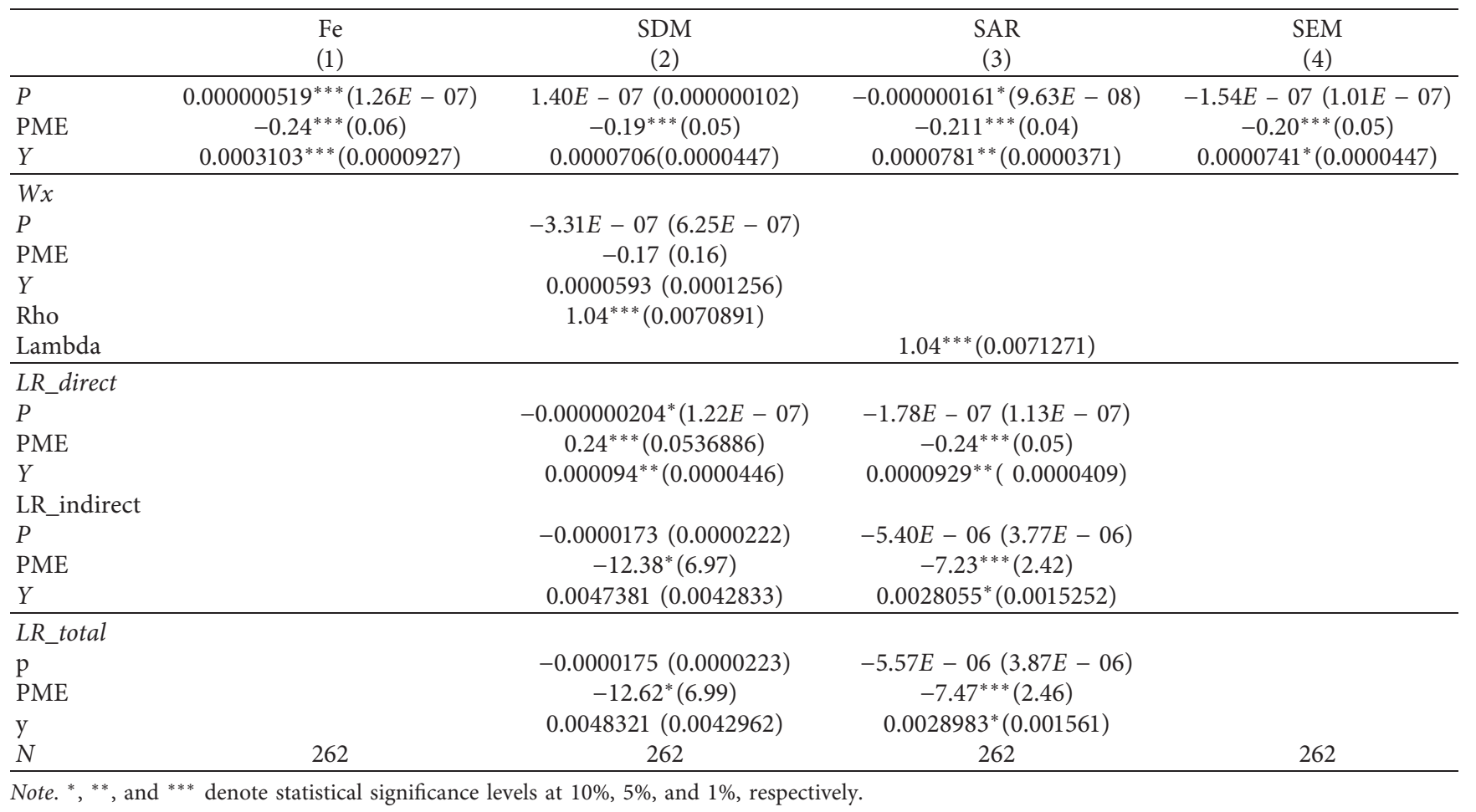

there were many turning points in the impacts of PME changes on PM2.5 concentrations, which again cannot be captured by regressions.

Given that serious PM2.5 emissions always occurred in large cities, we selected PME impacts in Beijing, Shanghai, Guangzhou, and Shenzhen for analysis. In particular, Beijing's PME impacts changed by about $-0.59,-14.84$, and $-4.50 \mathrm{ug} / \mathrm{m}^{3}$ in the periods of 2003-2006, 2006-2009, and 2013-2017, respectively; however, it increased by about $4.49 \mathrm{ug} / \mathrm{m}^{3}$ during 2009-2013. PME changes reduced Shanghai's PM2.5 concentrations from 2003 to 2006 $\left(-0.43 \mathrm{ug} / \mathrm{m}^{3}\right)$, while they increased by about $0.30,9.30$, and $8.18 \mathrm{ug} / \mathrm{m}^{3}$ during 2006-2009, 2009-2013, and 2013-2017, respectively. Guangzhou's PME changes had a negative impact during 2009-2013 $\left(-6.29 \mathrm{ug} / \mathrm{m}^{3}\right)$, while it stimulated PM2.5 concentrations in the other periods $(+4.34$,
+0.56 , and $+7.81 \mathrm{ug} / \mathrm{m}^{3}$ ). Shenzhen decreased its PM2.5 concentrations in 2003-2006 and 2009-2013 (-0.82 and $\left.-5.66 \mathrm{ug} / \mathrm{m}^{3}\right)$, but increased them in the periods 2006-2009 and 2013-2017 (+2.68 and $+2.91 \mathrm{ug} / \mathrm{m}^{3}$, resp.). Evidently, Beijing fared better than the other three cities in developing PME, especially after 2013; this is consistent with Yang et al. [14] and Zíková et al.'s [33] findings. The reasons for this may derive from the issuance and implementation of more stringent policies related to smog control in the Beijing-Tianjin-Hebei region in 2012, such as "Beijing-Tianjin-Hebei regional environmental protection takes the lead in breaking through the cooperation framework agreement," switching from coal consumption to natural gas consumption, and implementation of the Atmospheric Pollution Prevention and Control Action Plan $[11,34]$. 
TABle 2: Regression between provincial $\mathrm{CO}_{2}$ emissions and energy consumption based on the variable coefficient model.

\begin{tabular}{|c|c|c|c|}
\hline & Coefficient & Standard error & $P$-value \\
\hline $\begin{array}{l}\mathrm{CO}_{2} \text { emissions } \\
\text { id\#c. } \mathrm{CO}_{2} \text { emissions }\end{array}$ & 49.07 & 1.83 & $\leq 0.001$ \\
\hline Yunan & -23.22 & 2.16 & $\leq 0.001$ \\
\hline Inner Mongolia & 89.95 & 3.96 & $\leq 0.001$ \\
\hline Beijing & 17.42 & 4.23 & $\leq 0.001$ \\
\hline Jilin & -30.34 & 2.05 & $\leq 0.001$ \\
\hline Sichuan & 82.65 & 3.50 & $\leq 0.001$ \\
\hline Tianjin & -21.72 & 2.46 & $\leq 0.001$ \\
\hline Ningxia & 57.76 & 10.25 & $\leq 0.001$ \\
\hline Anhui & -12.96 & 2.30 & $\leq 0.001$ \\
\hline Shandong & 31.09 & 2.07 & $\leq 0.001$ \\
\hline Shanxi & 39.99 & 2.74 & $\leq 0.001$ \\
\hline Guangdong & 103.77 & 2.95 & $\leq 0.001$ \\
\hline Guangxi & -10.29 & 2.66 & $\leq 0.001$ \\
\hline Xinjiang & 11.02 & 2.89 & $\leq 0.001$ \\
\hline Jiangsu & -5.69 & 1.95 & 0.004 \\
\hline Jiangxi & -7.98 & 3.03 & 0.009 \\
\hline Hebei & 8.32 & 2.02 & $\leq 0.001$ \\
\hline Henan & 19.66 & 2.26 & $\leq 0.001$ \\
\hline Zhejiang & 71.60 & 3.38 & $\leq 0.001$ \\
\hline Hainan & -46.77 & 1.93 & $\leq 0.001$ \\
\hline Hubei & 9.60 & 2.42 & $\leq 0.001$ \\
\hline Hunan & 19.80 & 2.71 & $\leq 0.001$ \\
\hline Gansu & -35.43 & 2.02 & $\leq 0.001$ \\
\hline Gujian & 26.39 & 3.54 & $\leq 0.001$ \\
\hline Guizhou & 220.59 & 12.52 & $\leq 0.001$ \\
\hline Liaoning & -8.40 & 2.01 & $\leq 0.001$ \\
\hline Chongqing & -10.25 & 2.73 & $\leq 0.001$ \\
\hline Shaanxi & -16.14 & 2.31 & $\leq 0.001$ \\
\hline Qinghai & -44.93 & 1.91 & $\leq 0.001$ \\
\hline Heilongjiang & -0.97 & 2.48 & 0.690 \\
\hline$N$ & & 630 & \\
\hline$R$ & & 0.9861 & \\
\hline$F(30,600)$ & & $1420.9^{* * *}$ & \\
\hline
\end{tabular}

Note. ${ }^{*},{ }^{* *}$, and ${ }^{* * *}$ denote statistical significance levels at $10 \%, 5 \%$, and $1 \%$, respectively.

Figure 3 presents the impacts of the other four driving forces on PM2.5 concentrations. Potential emission intensity in 210 cities curbed PM2.5 concentrations, reflecting the optimization of the energy consumption structure. In particular, Jinchang $\left(-42.93 \mathrm{ug} / \mathrm{m}^{3}\right)$, Hengshui $\left(-40.87 \mathrm{ug} / \mathrm{m}^{3}\right)$, Anshan $(-38.13 \mathrm{ug} /$ $\left.\mathrm{m}^{3}\right)$, Daqing $\left(-37.39 \mathrm{ug} / \mathrm{m}^{3}\right)$, and Baoding $\left(-33.40 \mathrm{ug} / \mathrm{m}^{3}\right)$ were the top five cities whose potential emission intensity decreased PM2.5 concentrations during 2003-2017. Energy intensity had reduction effects on PM2.5 concentrations in all observed cities during 2003-2017, which is consistent with Chen et al. [11], Zhang et al. [16], and Li et al. [35]. The results indicate that the improvement in energy efficiency may be responsible for energy conservation, leading to the decline in PM2.5 concentrations. GDP per capita and population in almost all cities contributed to increasing PM2.5 concentrations during 2003-2017. Among them, Zhengzhou's GDP per capita and Shengzhen's population individually contributed to the highest increases, of 139.21 and $29.85 \mathrm{ug} / \mathrm{m}^{3}$, respectively.

3.3. PME for the Spatial Changes in PM2.5 Concentrations among Cluster Cities. Based on the above-described clustering methods, we divided the 262 cities into three groups. The first group was concentrated on the cities with the largest emissions intensity $\left(0.026 \mathrm{ug} / \mathrm{m}^{3 *}\right.$ million yuan, averagely); the second group had the middle emissions intensity $\left(0.006 \mathrm{ug} / \mathrm{m}^{3 *}\right.$ million yuan, averagely); and the third group's average emissions intensity were the lowest $\left(0.002 \mathrm{ug} / \mathrm{m}^{3 *}\right.$ million yuan). The detailed classification is presented in Appendix A, Table 3.

Then, we studied the impacts of PME changes on withingroup differences of PM2.5 concentrations. Figure 4 reports the impacts of PME on PM2.5 concentrations between each city and the classified group's average in 2003 and 2017.

Regarding the cities in the first group, 141 cities' PME contributed to negative differences within the first group's PM2.5 concentrations and reduced the within-group differences when the average PM2.5 concentrations in the first group in 2003 were set as the reference, indicating that these cities' PME did better than their average level. And there were 75 cities' PME stimulated within-group differences, implying that they failed to reach their groups' average level. Taking six cities in 2003 as examples, Daqing $(-176.31 \mathrm{ug} /$ $\left.\mathrm{m}^{3}\right)$, Taizhou $\left(-161.50 \mathrm{ug} / \mathrm{m}^{3}\right)$, and Xiamen $\left(-147.90 \mathrm{ug} / \mathrm{m}^{3}\right)$ 

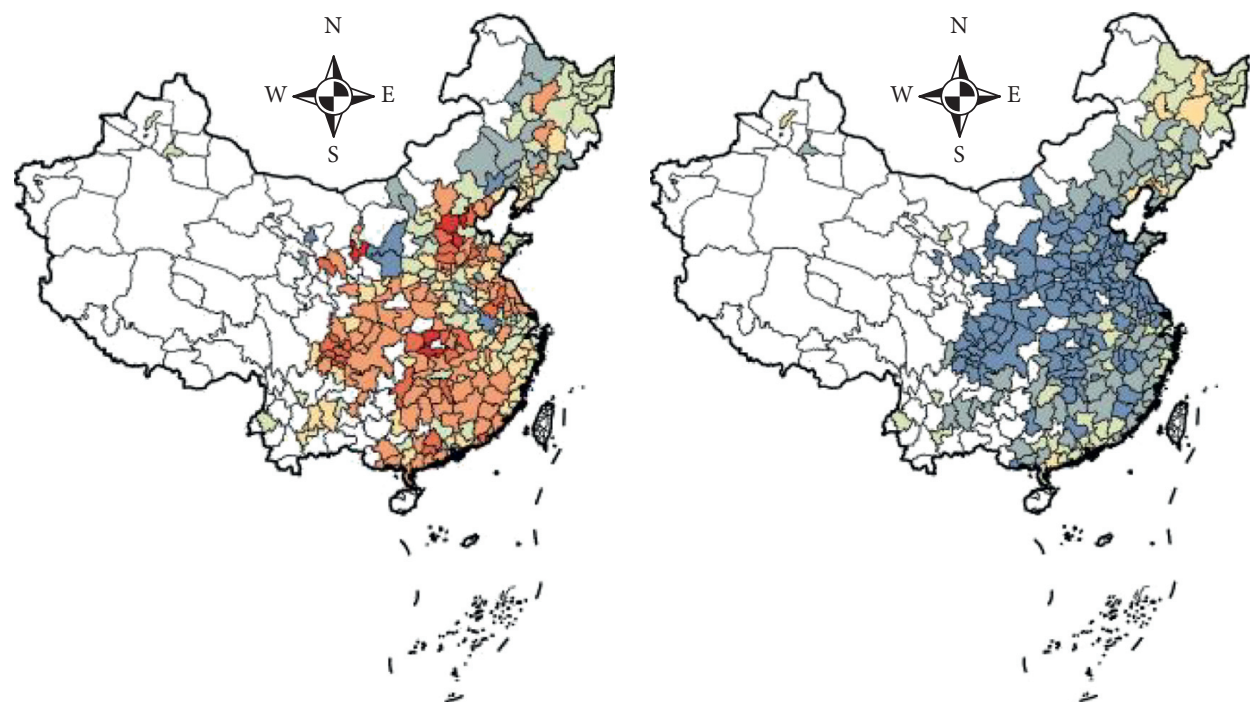

PME (2003-2006)

PME (2006-2009)

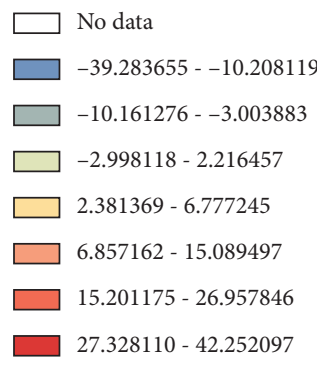

(a)

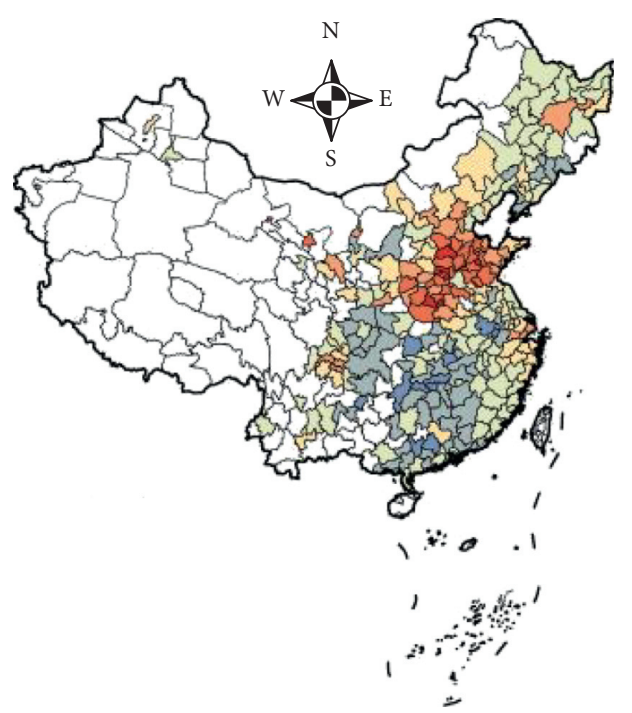

PME (2009-2013)

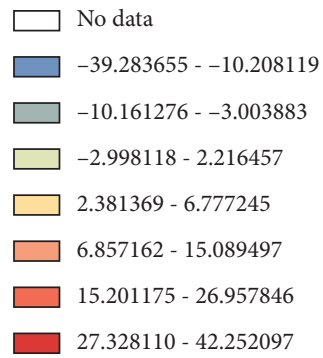

(c)

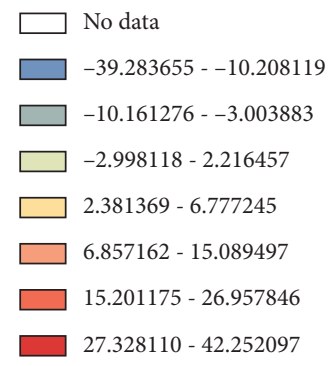

(b)

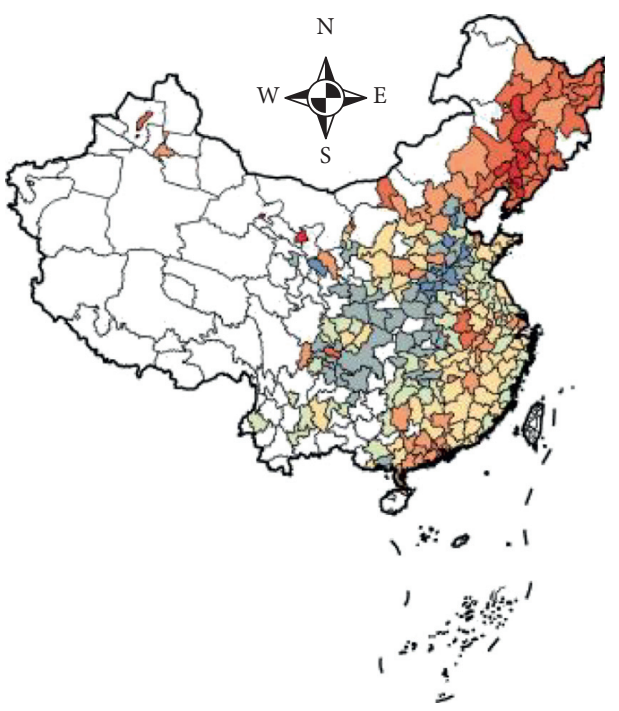

PME (2013-2017)

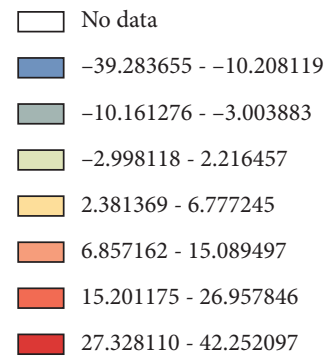

(d)

Figure 2: The effects of PME on PM2.5 concentrations during the periods of 2003-2006, 2006-2009, 2009-2013, and 2013-2017. 

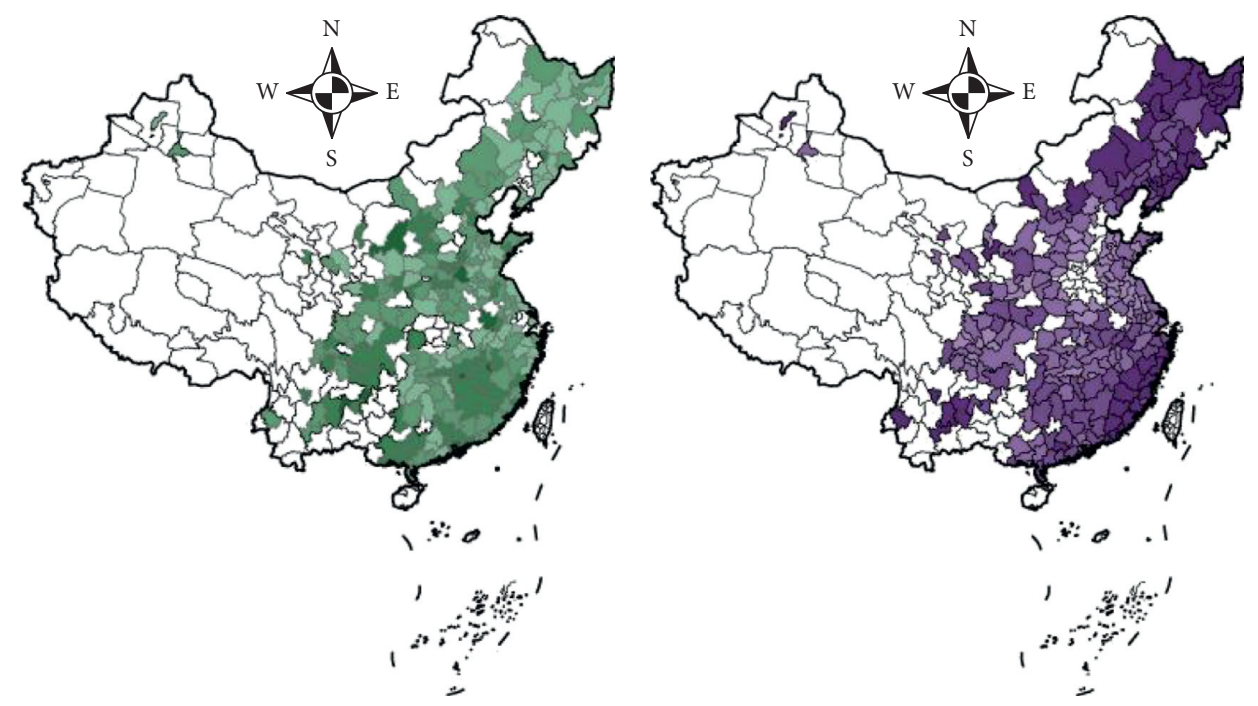

PPME (2003-2017)

EI (2003-2017)

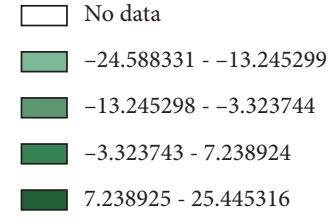

(a)

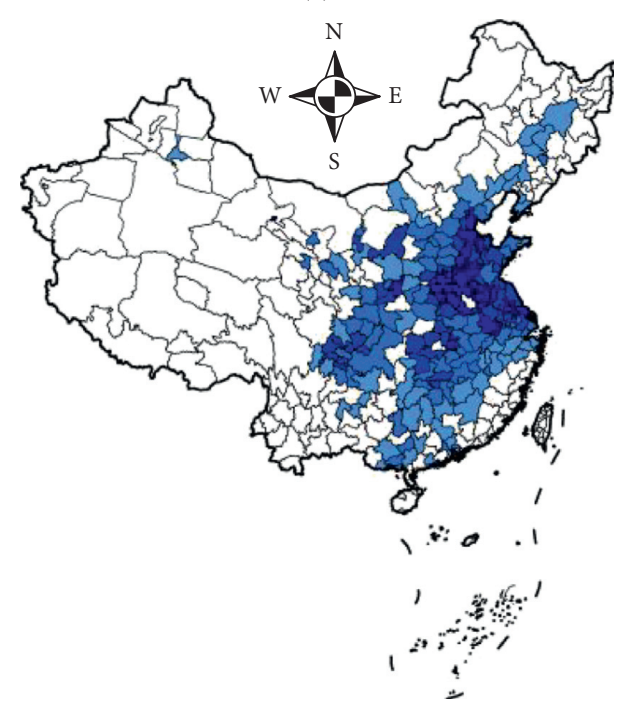

PI (2003-2017)

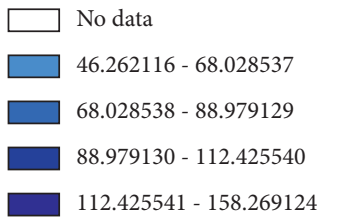

(c)

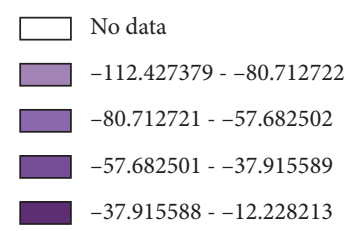

(b)

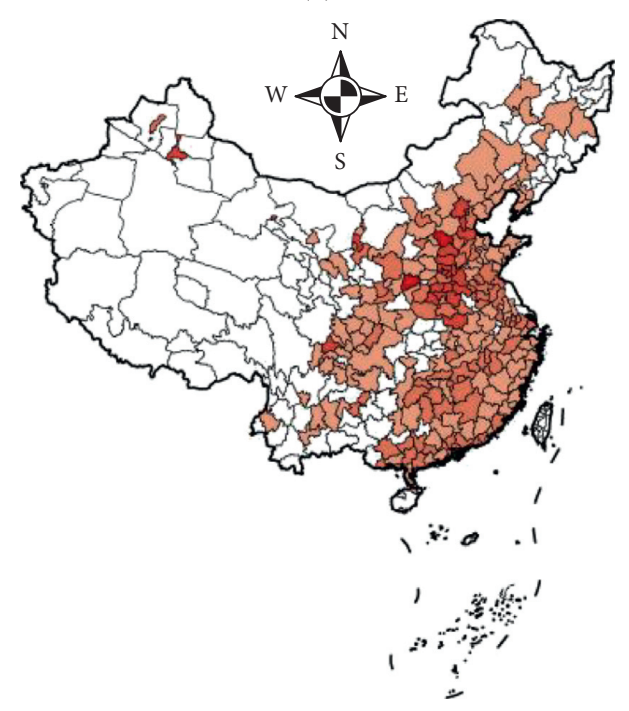

$\mathrm{P}(2003-2017)$
$\square$ No data
$\square \quad-0.108834-4.074874$
$\square \quad 4.074875-9.103045$
$\square \quad 9.103046-17.347640$
$\square \quad 17.347641-29.845250$

(d)

FIGURE 3: The effects of potential emission intensity, energy intensity, GDP per capita, and population on PM2.5 concentrations during 2003-2017. 
TABLE 3: List of city clusters.

\begin{tabular}{|c|c|c|}
\hline Cluster & City name & $\begin{array}{c}\text { Number of } \\
\text { cities }\end{array}$ \\
\hline First group & $\begin{array}{l}\text { Ankang, Anqing, Anshun, Anyang, Anshan, Bazhong, Baicheng, Baishan, Baiyin, Bengbu, Baotou, Baoji, } \\
\text { Baoding, Baoshan, Beihai, Benxi, Binzhou, Cangzhou, Changde, Chaoyang, Chaozhou, Chenzhou, } \\
\text { Chengde, Chizhou, Chifeng, Chuzhou, Dazhou, Daqing, Datong, Dandong, Deyang, Dezhou, Dongying, } \\
\text { Fangchenggang, Fushun, Fuzhou, Fuxin, Fuyang, Ganzhou, Guang'an, Guangyuan, Guigang, Guiyang, } \\
\text { Guilin, Haikou, Handan, Hanzhong, Heyuan, Heze, Hebi, Hegang, Heihe, Hengshui, Hengyang, Hohhot, } \\
\text { Huludao Huaihua, Huai'an, Huaibei, Huainan, Huanggang, Huangshan, Huangshi, Jixi, Jian, Jilin, Jiamusi, } \\
\text { Jiaxing, Jiayuguan, Jiangmen, Jiaozuo, Jieyang, Jinchang, Jinhua, Jinzhou, Jincheng, Jinzhong, Jingmen, } \\
\text { Jingdezhen, Jiujiang, Kaifeng, Karamay, Laiwu, Lanzhou, Langfang, Leshan, Lishui, Lianyungang, } \\
\text { Liaoyang, Liaoyuan, Liaocheng, Linfen, Linyi, Liuzhou, Liuan, Liupanshui, Longyan, Loudi, Luzhou, } \\
\text { Luoyang, Luohe, Ma'anshan, Maoming, Meishan, Meizhou, Mianyang, Mudanjiang, Nanchong, Nanning, } \\
\text { Nanping, Neijiang, Ningde, Panzhihua, Panjin, Pingdingshan, Pingxiang, Putian, Puyang, Qitaihe, Qiqihar, } \\
\text { Qinzhou, Qinhuangdao, Qingyuan, Quzhou, Qujing, Rizhao, Sanmenxia, Sanming, Sanya, Xiamen, } \\
\text { Shantou, Shanwei, Shangqiu, Shangrao, Shaoguan, Shaoyang, Shiyan, Shizuishan, Shuangyashan, } \\
\text { Shuozhou, Siping, Songyuan, Suihua, Suizhou, Suining, Taizhou, Taiyuan, Taian, Tianshui, Tieling, } \\
\text { Tonghua, Tongliao, Tongchuan, Tongling, Weihai, Weinan, Wuhai, Urumqi, Wuhu, Wuzhong, Wuzhou, } \\
\text { Xining, Xianning, Xianyang, Xiangtan, Xiaogan, Xinzhou, Xinxiang, Xinyu, Xinyang, Xingtai, Suqian, } \\
\text { Suzhou, Xuchang, Xuancheng, Ya’an, Yan'an, Yangjiang, Yangquan, Yichun, Yibin, Yichang, Yichun, } \\
\text { Yiyang, Yinchuan, Yingtan, Yingkou, Yongzhou, Yulin, Yuxi, Yueyang, Yunfu, Yuncheng, Zaozhuang, } \\
\text { Zhanjiang, Zhangjiajie, Zhangjiakou, Zhangzhou, Changzhi, Zhaoqing, Zhenjiang, Zhongshan, Zhoushan, } \\
\text { Zhoukou, Zhuhai, Zhuzhou, Zhumadian, Ziyang, Zigong, Zunyi }\end{array}$ & 216 \\
\hline $\begin{array}{l}\text { Second } \\
\text { group }\end{array}$ & $\begin{array}{c}\text { Changzhou, Chengdu, Dalian, Dongguan, Foshan, Fuzhou, Harbin, Hangzhou, Hefei, Jinan, Jining, } \\
\text { Kunming, Nanchang, Nanjing, Nantong, Ningbo, Qingdao, Quanzhou, Shaoxing, Shenyang, Shijiazhuang, } \\
\text { Taizhou, Tangshan, Weifang, Wenzhou, Wuxi, Wuhan, Xi’an, Xuzhou, Yantai, Yancheng, Yangzhou, } \\
\text { Changchun, Changsha, Zhengzhou, Zibo }\end{array}$ & 36 \\
\hline Third group & Beijing, Guangzhou, Shanghai, Shenzhen, Suzhou, Tianjin, Chongqing & 7 \\
\hline
\end{tabular}

$*, * *$, and $* * *$ denote statistical significance levels at $10 \%, 5 \%$, and $1 \%$, respectively.
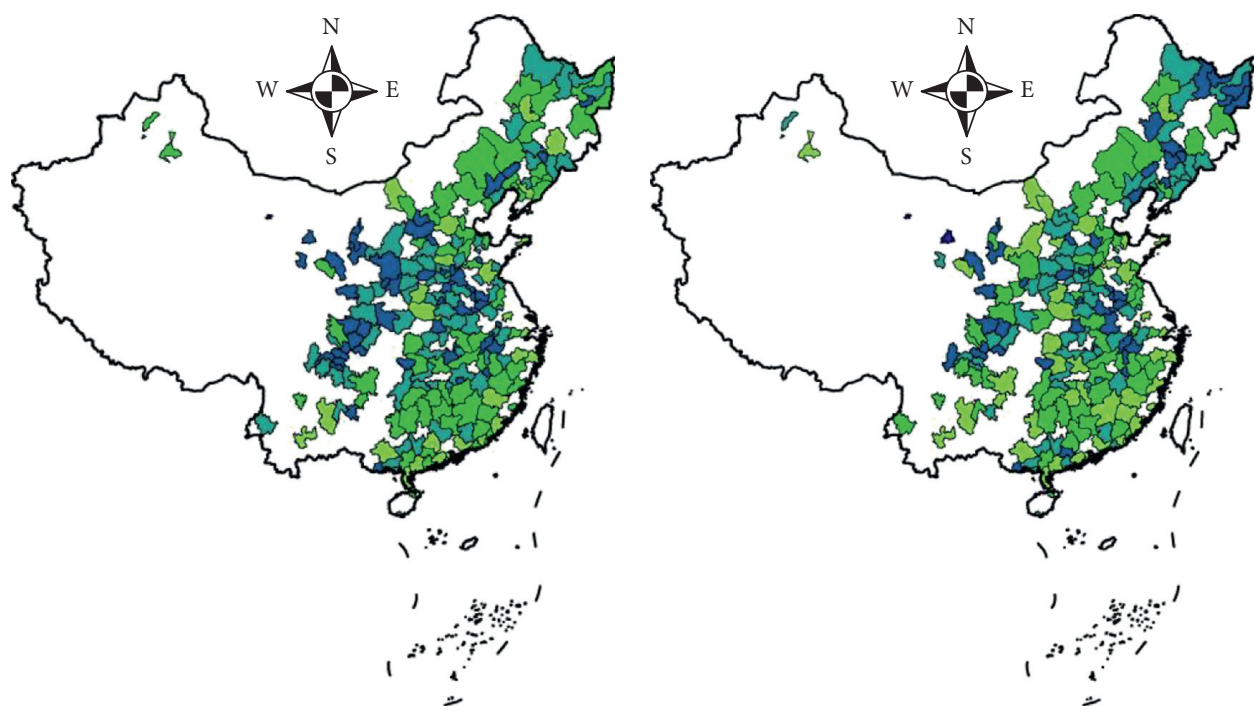

The first group (2003)

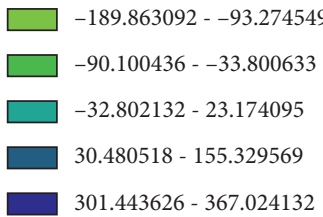

(a)

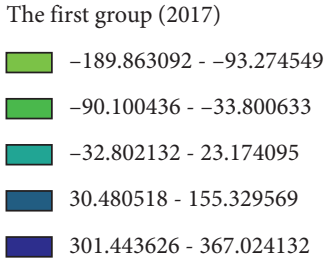

(b)

FIgURE 4: Continued. 

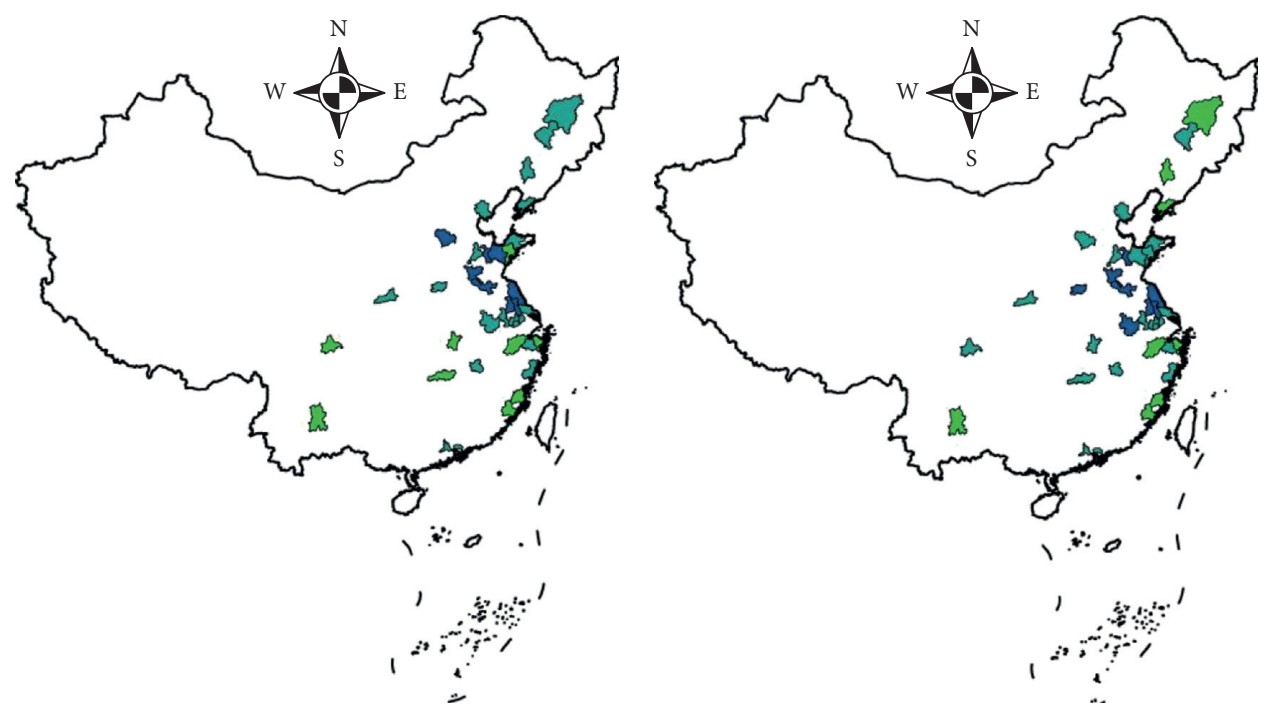

The second group (2003)

The second group (2017)

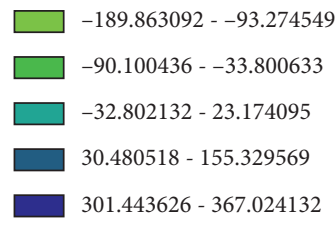

(c)

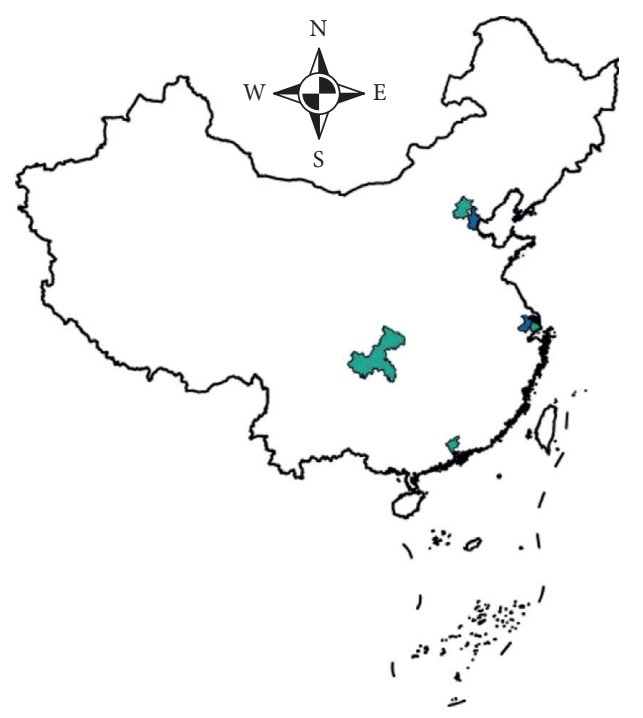

The third group (2003)

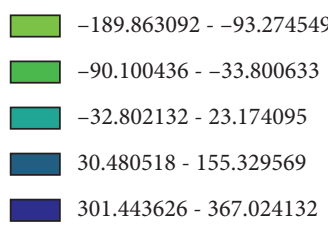

(e)

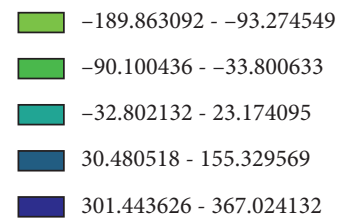

(d)

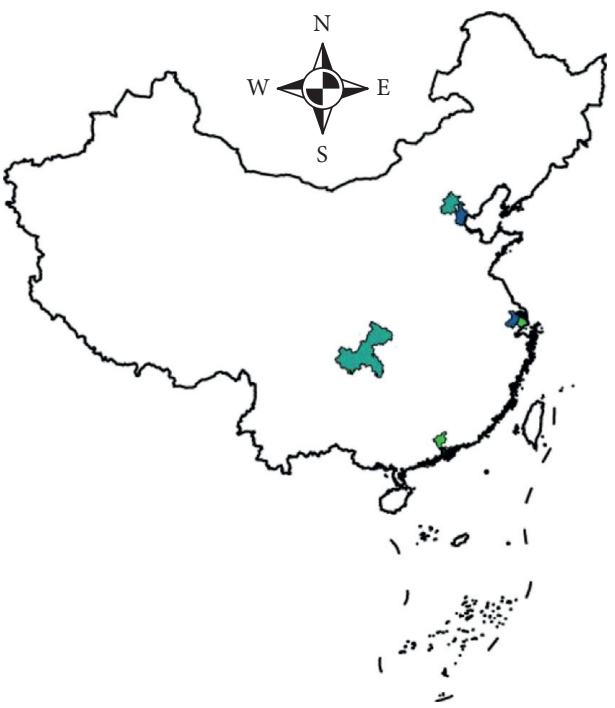

The third group (2017)

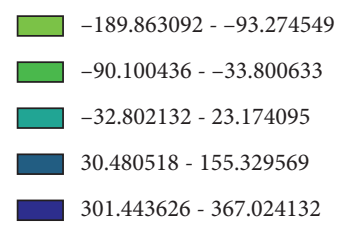

(f)

Figure 4: The impacts of emission reduction technological changes on PM2.5 concentrations between each city and the classified group's average. 
were the top three cities with negative differences. Meanwhile, Jiayuguan $\left(+270.48 \mathrm{ug} / \mathrm{m}^{3}\right)$, Jinchang $\left(+152.6 \mathrm{ug} / \mathrm{m}^{3}\right)$, and Tongchuan $\left(+151.10 \mathrm{ug} / \mathrm{m}^{3}\right)$ were the top three cities that contributed to positive within-group differences. Compared with 2003, there were several changes in the spatial decomposition results in 2017: 147 cities' PME lowered the between-emissions differences within the first group's PM2.5 concentrations, but PME changes in 69 cities caused a positive within-group gap. For example, Ankang city's PME reduced the within-group gap in 2013 (-54.28 ug/ $\mathrm{m}^{3}$ ) but failed in $2017\left(+9.82 \mathrm{ug} / \mathrm{m}^{3}\right)$.

In the second group, the PME in 20 cities led to reductions in the within-group differences in 2003, and 16 cities' emission reductions caused positive within-group differences. Particularly, PME in the cities of Quanzhou $\left(-51.10 \mathrm{ug} / \mathrm{m}^{3}\right)$, Hangzhou $\left(-50.30 \mathrm{ug} / \mathrm{m}^{3}\right)$, and Fuzhou $\left(-47.35 \mathrm{ug} / \mathrm{m}^{3}\right)$ contributed to a decline in the within-group difference, while Hefei $\left(+54.07 \mathrm{ug} / \mathrm{m}^{3}\right)$, Taizhou $(+52.57 \mathrm{ug} /$ $\left.\mathrm{m}^{3}\right)$, and Jining $\left(+51.09 \mathrm{ug} / \mathrm{m}^{3}\right)$ saw an increase of the within-group gap. Moreover, there were 18 cities in which PME helped to reduce the within-group differences in 2017, implying that the spatial differences did not change much in these cities.

With regard to the third group, PME in the first-tier cities (Shanghai, $-53.98 \mathrm{ug} / \mathrm{m}^{3}$; Guangzhou, $-35.47 \mathrm{ug} / \mathrm{m}^{3}$; Shenzhen, $-30.03 \mathrm{ug} / \mathrm{m}^{3}$; and Beijing, $-14.17 \mathrm{ug} / \mathrm{m}^{3}$ ) contributed to reductions in the within-group differences in 2003. However, the PME of Tianjin, Suzhou, and Chongqing increased to $55.82,24.16$, and $19.30 \mathrm{ug} / \mathrm{m}^{3}$ of the within-group differences, respectively. In 2017, the four first-tier cities' and Chongqing city's PME changes were responsible for the negative withingroup differences (Shanghai, $-18.89 \mathrm{ug} / \mathrm{m}^{3}$; Guangzhou, $-16.15 \mathrm{ug} / \mathrm{m}^{3}$; Shenzhen, $-27.79 \mathrm{ug} / \mathrm{m}^{3}$; Beijing, $-24.41 \mathrm{ug} /$ $\mathrm{m}^{3}$; and Chongqing, $-10.41 \mathrm{ug} / \mathrm{m}^{3}$ ), and the remaining cities still contributed to positive within-group gaps (Tianjin, $+18.89 \mathrm{ug} / \mathrm{m}^{3}$; Suzhou, $+35.19 \mathrm{ug} / \mathrm{m}^{3}$ ).

In summary, since most cities' PME contributed to negative impacts on the within-group differences, indicating that most cities' PME was better than their group's average level. However, it also should be noted that the PME of a small number of cities, such as Jiayuguan city and Tongchuan city, were lower than their groups' average level and had a very weak impact on curbing PM2.5 concentrations, which is consistent with the results proposed by Zhang et al. [16]. At the same time, the distributions of the spatial decomposition of the three groups were stable in the period of 2002-2017, implying that the catch-up effect within the group was not obvious. Thus, the governments should focus more on regional heterogeneity when encouraging the promotion of PM2.5 emission reduction technologies.

\section{Conclusions}

This study explored the impacts of PME changes on the PM2.5 concentrations of 262 Chinese cities during 2002-2017. First, we applied three spatial econometric models (SDM, SAR, and SEM), identifying the spatial autocorrelation and potential relationship between PME changes and PM2.5 concentrations. Furthermore, we decomposed the temporal and spatial changes in the 262 cities' PM2.5 concentrations based on a combination of LMDI and $k$-means clustering methods. In terms of the temporal changes, we found that most cities' PME impacts fluctuated during 2002-2017, and there were many turning points, indicating that the reduction effects in many cities were not stable. However, energy intensity continuously played a significant role in decreasing PM2.5 concentrations due to energy conservation caused by the improvement in energy efficiency. With regard to the spatial decomposition based on clusters, we found that most cities' PME contributed to negative differences, implying that the PME in a small number of cities, such as Jiayuguan City and Jinchang City, was not strong and lowered the average level of their group. At the same time, the distributions of the spatial decomposition of the three groups were stable in the period 2002-2017, implying that a catch-up effect within the group was not obvious.

Based on the analysis, we provide several policy implications for curbing PM2.5 concentrations from a socioeconomic perspective. First, although the results, based on econometric methods, show that PME progress had significant curbing impacts on China's city-level PM2.5 concentrations, the temporal and regional heterogeneity cannot be ignored. Given that the PME failed to continuously decrease China's city-level PM2.5 concentration, China's cities should pay more attention to increased fiscal expenditures in technological innovations, such as composite carbon slurry clean combustion technology, supercritical flue gas desulfurization (FGD) systems, and ultra-supercritical FGD systems [21, 35].

Second, in addition to increasing PME, it is important to promote the application of energy-saving technologies and the optimization of energy use structures. In light of the effects of energy intensity on PM2.5 concentrations, the promotion of energy efficiency will reduce the energy input, thus reducing PM2.5 emissions and concentrations under the same conditions of PME. In addition, since PM2.5 pollution is mainly driven by fossil fuel combustion [36], speeding up the use of clean energy would also significantly reduce PM2.5 concentration.

Third, considering that the spatial impacts of PME were relatively stable over time, regional advanced emission reduction technological innovations should be promoted around and selected as demonstrations so that the catchingup effects within group will be highlighted.

\section{Appendix}

The temporal impacts of drivers on PM2.5 concentration can be estimated based on equations (A2.1)-(A2.5):

$$
\begin{gathered}
\Delta P M_{i, P P M E}^{b, t}=\frac{\left(P M_{i}^{t}-P M_{i}^{b}\right)}{\ln \left(P M_{i}^{t} / P M_{i}^{b}\right)} \times \ln \left(\frac{P P M E_{i}^{t}}{P P M E_{i}^{b}}\right), \\
\Delta P M_{i, E I}^{b, t}=\frac{\left(P M_{i}^{t}-P M_{i}^{b}\right)}{\ln \left(P M_{i}^{t} / P M_{i}^{b}\right)} \times \ln \left(\frac{E I_{i}^{t}}{E I_{i}^{b}}\right),
\end{gathered}
$$




$$
\begin{gathered}
\Delta P M_{i, P I}^{b, t}=\frac{\left(P M_{i}^{t}-P M_{i}^{b}\right)}{\ln \left(P M_{i}^{t} / P M_{i}^{b}\right)} \times \ln \left(\frac{P I_{i}^{t}}{P I_{i}^{b}}\right), \\
\Delta P M_{i, P}^{b, t}=\frac{\left(P M_{i}^{t}-P M_{i}^{b}\right)}{\ln \left(P M_{i}^{t} / P M_{i}^{b}\right)} \times \ln \left(\frac{P_{i}^{t}}{P_{i}^{b}}\right), \\
\Delta P M_{i, P M E}^{b, t}=\frac{\left(P M_{i}^{t}-P M_{i}^{b}\right)}{\ln \left(P M_{i}^{t} / P M_{i}^{b}\right)} \times \ln \left(\frac{P M E_{i}^{t}}{P M E_{i}^{b}}\right),
\end{gathered}
$$

where $\triangle P M_{i, P P M E}^{b, t}$ denotes the impacts of potential emission intensity on the $i$ th city's PM2.5 concentration from period $b$ to $t ; \triangle P M_{i, E I}^{b, t}$ denotes the impacts of energy intensity on the $i$ th city's PM2.5 concentration from period $b$ to $t ; \Delta P M_{i, P I}^{b, t}$ denotes the impacts of GDP per capita on the ith city's PM2.5 concentration from period $b$ to $t ; \Delta P M_{i, P}^{b, t}$ denotes the impacts of population on the ith city's PM2.5 concentration from period $b$ to $t$; and $\triangle P M_{i, P M E}^{b, t}$ denotes the impacts of PM2.5 emission efficiency on the $i$ th city's PM2.5 concentration from period $b$ to $t$.

Similarly, based on the definite reference, the spatial LMDI method can also be used for spatial decomposition; the corresponding formulas are presented as follows:

$$
\begin{gathered}
\Delta P M_{i, P P M E}^{r}=\frac{\left(P M_{i}^{t}-P M_{r}^{t}\right)}{\ln \left(P M_{i}^{t} / P M_{r}^{t}\right)} \times \ln \left(\frac{P P M E_{i}^{t}}{P P M E_{r}^{t}}\right), \\
\Delta P M_{i, E I}^{r}=\frac{\left(P M_{i}^{t}-P M_{r}^{t}\right)}{\ln \left(P M_{i}^{t} / P M_{r}^{t}\right)} \times \ln \left(\frac{E I_{i}^{t}}{E I_{r}^{t}}\right), \\
\Delta P M_{i, P I}^{r}=\frac{\left(P M_{i}^{t}-P M_{r}^{t}\right)}{\ln \left(P M_{i}^{t} / P M_{r}^{t}\right)} \times \ln \left(\frac{P I_{i}^{t}}{P I_{r}^{t}}\right), \\
\Delta P M_{i, P}^{r}=\frac{\left(P M_{i}^{t}-P M_{r}^{t}\right)}{\ln \left(P M_{i}^{t} / P M_{r}^{t}\right)} \times \ln \left(\frac{P_{i}^{t}}{P_{r}^{t}}\right), \\
\Delta P M_{i, P M E}^{r}=\frac{\left(P M_{i}^{t}-P M_{r}^{t}\right)}{\ln \left(P M_{i}^{t} / P M_{r}^{t}\right)} \times \ln \left(\frac{P M E_{i}^{t}}{P M E_{r}^{t}}\right),
\end{gathered}
$$

where $\triangle P M_{i, P P M E}^{r}$ denotes the gap between the impacts of potential emission intensity on the ith city's PM2.5 concentration and the reference; $\triangle P M_{i, E I}^{r}$ denotes the gap between the impacts of energy intensity on the ith city's PM2.5 concentration and the reference; $\triangle P M_{i, P I}^{r}$ denotes the difference between effects of GDP per capita on the ith city's PM2.5 concentration and the reference; $\triangle P M_{i, P}^{r}$ denotes the gap between the effects of population on the ith city's PM2.5 concentration; and the reference $\triangle P M_{i, P M E}^{r}$ denotes the gap between the impacts of PM2.5 emission efficiency on the $i$ th city's PM2.5 concentration and the reference.

\section{Data Availability}

The data can be obtained upon request from the corresponding author.

\section{Additional Points}

PM2.5 emission reduction technology (PME) was estimated for 262 cities. The 262 cities were classified into three groups based on the $k$-means cluster method. The curbing impacts of PME on PM2.5 were fluctuated and unstable. Energy intensity played a more stable role in PM2.5 emissions reductions. The catch-up and transcendence effects of PME within the group were limited.

\section{Conflicts of Interest}

The authors declare that there are no conflicts of interest regarding the publication of this paper.

\section{Acknowledgments}

This work was supported by the National Key Natural Science Foundation of China (Grant no. 71934001), the National Natural Science Foundation of China (Grant nos. 71471001, 41771568, 71533004, and 71503001), the National Key Research and Development Program of China (Grant no. 2016YFA0602500), Sichuan Province Social Science High-Level Research Team Building Program, and the Program for Major Projects in Philosophy and Social Science Research under China's Ministry of Education (Grant no. 14JZD031).

\section{References}

[1] R. T. Burnett, C. A. Pope III, M. Ezzati et al., "An integrated risk function for estimating the global burden of disease attributable to ambient fine particulate matter exposure," Environmental Health Perspectives, vol. 122, no. 4, pp. 397-403, 2014.

[2] X. Ji, Y. Yao, and X. Long, "What causes PM2.5 pollution? Cross-economy empirical analysis from socioeconomic perspective," Energy Policy, vol. 119, pp. 458-472, 2018.

[3] K. Park, T. Yoon, C. Shim, E. Kang, Y. Hong, and Y. Lee, "Beyond strict regulations to achieve environmental and economic health-an optimal PM2.5 mitigation policy for Korea," International Journal of Environmental Research and Public Health, vol. 17, no. 16, p. 5725, 2020.

[4] R. Wu, H. Dai, Y. Geng et al., "Economic impacts from PM2.5 pollution-related health effects: a case study in Shanghai," Environmental Science and Technology, vol. 51, no. 9, pp. 5035-5042, 2017.

[5] H. Yin, M. Pizzol, and L. Xu, "External costs of PM2.5 pollution in Beijing, China: uncertainty analysis of multiple health impacts and costs," Environmental Pollution, vol. 226, pp. 356-369, 2017.

[6] G. Yu, F. Wang, J. Hu, Y. Liao, and X. Liu, "Value assessment of health losses caused by PM2.5 in Changsha City, China," International Journal of Environmental Research and Public Health, vol. 16, no. 11, p. 2063, 2019.

[7] F. Dong, B. Yu, and Y. Pan, "Examining the synergistic effect of CO2 emissions on PM2.5 emissions reduction: evidence from China," Journal of Cleaner Production, vol. 223, pp. 759-771, 2019.

[8] W. Fan, S. Wang, X. Gu, Z. Q. Zhou, Y. Zhao, and W. D. Huo, "Evolutionary game analysis on industrial pollution control of 
local government in China," Journal of Environmental Management, vol. 298, p. 113499, 2021.

[9] J. Liu, Y. Han, X. Tang, J. Zhu, and T. Zhu, "Estimating adult mortality attributable to PM2.5 exposure in China with assimilated PM2.5 concentrations based on a ground monitoring network," The Science of the Total Environment, vol. 568, pp. 1253-1262, 2016.

[10] Q. Xiao, G. Geng, F. Liang et al., "Changes in spatial patterns of PM2.5 pollution in China 2000-2018: impact of clean air policies," Environment International, vol. 141, Article ID 105776, 2020.

[11] J. Chen, M. Gao, D. Li, L. Li, M. Song, and Q. Xie, "Changes in PM2.5 emissions in China: an extended chain and nested refined laspeyres index decomposition analysis," Journal of Cleaner Production, vol. 294, Article ID 126248, 2021.

[12] W. Lyu, Y. Li, D. Guan, H. Zhao, Q. Zhang, and Z. Liu, "Driving forces of Chinese primary air pollution emissions: an index decomposition analysis," Journal of Cleaner Production, vol. 133, pp. 136-144, 2016.

[13] G. Xu, X. Ren, K. Xiong, L. Li, X. Bi, and Q. Wu, "Analysis of the driving factors of PM2.5 concentration in the air: a case study of the Yangtze River Delta, China," Ecological Indicators, vol. 110, Article ID 105889, 2020.

[14] J. Yang, D. Song, D. Fang, and F. Wu, "Drivers of consumption-based PM2.5 emission of Beijing: a structural decomposition analysis," Journal of Cleaner Production, vol. 219, pp. 734-742, 2019.

[15] Y. R. Ma, Q. Ji, and Y. Fan, "Spatial linkage analysis of the impact of regional economic activities on PM2.5 pollution in China," Journal of Cleaner Production, vol. 139, pp. 11571167, 2016.

[16] Y. Zhang, C. Shuai, J. Bian, X. Chen, Y. Wu, and L. Shen, "Socioeconomic factors of PM2.5 concentrations in 152 Chinese cities: decomposition analysis using LMDI," Journal of Cleaner Production, vol. 218, pp. 96-107, 2019.

[17] J. Chen, M. Gao, M. Shahbaz, S. Cheng, and M. Song, "An improved decomposition approach toward energy rebound effects in China: review since 1992," Renewable and Sustainable Energy Reviews, vol. 145, Article ID 111141, 2021.

[18] J. Chen, S. Wang, C. Zhou, and M. Li, "Does the path of technological progress matter in mitigating China's PM2.5 concentrations? Evidence from three urban agglomerations in China," Environmental Pollution, vol. 254, Article ID 113012, 2019.

[19] D. Li, M. Gao, W. Hou, M. Song, and J. Chen, "A modified and improved method to measure economy-wide carbon rebound effects based on the PDA-MMI approach," Energy Policy, vol. 147, Article ID 111862, 2020.

[20] N. Xu, F. Zhang, and X. Xuan, "Impacts of industrial restructuring and technological progress on PM2.5 Pollution: evidence from prefecture-level cities in China," International Journal of Environmental Research and Public Health, vol. 18, no. 10, p. 5283, 2021.

[21] Q. Wang, Y. H. Chiu, and C. R. Chiu, "Driving factors behind carbon dioxide emissions in China: a modified productiontheoretical decomposition analysis," Energy Economics, vol. 51, pp. 252-260, 2015.

[22] J. Chen, M. Gao, K. Ma, and M. Song, "Different effects of technological progress on China's carbon emissions based on sustainable development," Business Strategy and the Environment, vol. 29, no. 2, pp. 481-492, 2020.

[23] P. Zhou and B. W. Ang, "Decomposition of aggregate $\mathrm{CO}_{2}$ emissions: a production-theoretical approach," Energy Economics, vol. 30, no. 3, pp. 1054-1067, 2008.
[24] S. Cheng, Y. Chen, F. Meng, J. Chen, G. Liu, and M. Song, "Impacts of local public expenditure on $\mathrm{CO} 2$ emissions in Chinese cities: a spatial cluster decomposition analysis," Resources, Conservation and Recycling, vol. 164, Article ID 105217, 2021.

[25] A. Likas, N. Vlassis, and J. J. Verbeek, "The global k-means clustering algorithm," Pattern Recognition, vol. 36, no. 2, pp. 451-461, 2003.

[26] H. Ralambondrainy, "A conceptual version of the k-means algorithm," Pattern Recognition Letters, vol. 16, no. 11, pp. 1147-1157, 1995.

[27] L. H. Juang and M. N. Wu, "Psoriasis image identification using k-means clustering with morphological processing," Measurement, vol. 44, no. 5, pp. 895-905, 2011.

[28] P. Trebuňa and J. Halčinová, "Experimental modelling of the cluster analysis processes," Procedia Engineering, vol. 48, pp. 673-678, 2012.

[29] J. Chen, M. Gao, S. Cheng et al., "China's city-level carbon emissions during 1992-2017 based on the inter-calibration of nighttime light data," Scientific Reports, vol. 11, no. 1, pp. 1-13, 2021.

[30] J. Chen, S. Cheng, M. Song, and J. Wang, "Interregional differences of coal carbon dioxide emissions in China," Energy Policy, vol. 96, pp. 1-13, 2016.

[31] X. Chen, F. Li, J. Zhang, W. Zhou, X. Wang, and H. Fu, "Spatiotemporal mapping and multiple driving forces identifying of PM2.5 variation and its joint management strategies across China," Journal of Cleaner Production, vol. 250, Article ID 119534, 2020b.

[32] Y. Hao and Y. M. Liu, "The influential factors of urban PM2.5 concentrations in China: a spatial econometric analysis," Journal of Cleaner Production, vol. 112, pp. 1443-1453, 2016.

[33] N. Zíková, Y. Wang, F. Yang, X. Li, M. Tian, and P. K. Hopke, "On the source contribution to Beijing PM2.5 concentrations," Atmospheric Environment, vol. 134, pp. 84-95, 2016.

[34] M. Tan, E. Ayhan, and M. Baydas, "Sustainability and cleaner production: case of textile and clothing sectors in Bingöl," The Journal of MacroTrends in Energy and Sustainability, vol. 4, no. 1, pp. 22-33, 2016.

[35] G. Li, C. Fang, and S. He, "The influence of environmental efficiency on PM2.5 pollution: evidence from 283 Chinese prefecture-level cities," The Science of the Total Environment, vol. 748, Article ID 141549, 2020 b.

[36] L. Li, Y. Lei, S. Wu et al., "Evaluation of future energy consumption on PM2.5 emissions and public health economic loss in Beijing," Journal of Cleaner Production, vol. 187, pp. 1115-1128, 2018. 